Library Collections, Acquisitions, \& Technical Services, v.24, no.2, Summer 2000, p.153-170

(C2001, Elsevier Science Inc.

\title{
THE IMPACT OF WEB PUBLISHING ON THE ORGANIZATION OF CATALOGING FUNCTIONS
}

\author{
Mary Grenci \\ Serials Catalog Librarian, University of Oregon
}

\begin{abstract}
Cataloging rules have long been organized according to the physical format and monograph versus serial nature of publications. This organization of the rules has resulted in the rise of several typical organizational models that make these same delineations. Web publishing is having a profound effect on both the nature of publications and the number of electronic resources being published and selected for inclusion in library catalogs, and is causing a major shift in the type of materials finding their way into cataloging workflows. Institutions that organize their cataloging functions according to one of the traditional models are finding themselves increasingly unable to meet the demands being placed upon them in this new environment. Traditional models of organization can, and must, be modified in order to successfully deal with this problem.
\end{abstract}

\section{Introduction}

Cataloging rules have for many years been organized according to the physical format and monograph versus serial nature of publications, and this organization of the rules has had a strong and lasting impact on the organization of cataloging functions, particularly in large libraries. The result has been the rise of several typical organizational models that make these same delineations in workflow.

The increase of publishing via the World Wide Web (hereafter called "the Web") has had a profound impact on three areas that are central to the workload and workflow of technical services functions in most libraries: 1) the nature of publications (i.e. whether they are monograph or serial); 2) the number of computer files being published; and 3) a growing trend in libraries to provide access to (that is, to collect) materials that are available remotely via the Web. The combination of these factors has resulted in a major shift in the nature of materials finding their way into cataloging workflows, causing many cataloging administrators to struggle with how best to handle this (to coin the current buzzword) "paradigm shift." With no ideal solution at hand, they are looking for the best route through shifting expectations. This article seeks to provide a solid context for the current environment; discuss some traditional models for organization of cataloging functions, including how well they are (or are not) working in 
libraries today; offer ideas on how to make various organizational structures work better in this environment; and, finally, put forth a possible solution to the problem.

\section{Context}

\section{Organization of Cataloging Functions}

A literature review, undertaken in order to ascertain the most common methods of organizing cataloging functions both today and in the recent past, yielded little of value to the development of an overall picture. Because this article is concerned with the effect of Web publishing and collection of Web resources on cataloging workflows, the author scanned the literature for information concerning the number of organizations that divide cataloging functions along lines of monograph and serial and/or by physical format with the goal of determining if there has been a verifiable shift in this area over the past two decades.

The literature includes numerous articles and reports concerning the organization and reorganization of cataloging functions within particular libraries, and organization charts are commonly found at library Web sites. However, this author found no resource containing statistics on how many libraries organize cataloging in one way versus how many organize it another way. The most useful data of this type was found in several Association of Research Libraries (ARL) SPEC Kits showing organization charts and reorganization data from research libraries responding to various surveys. The data, however, are inconclusive for the purposes of this article and do not yield a clear picture for even this one type of library.

SPEC Kit no.1 (published in 1973, updated in 1977) includes a total of 15 organization charts of use in this study. Eight of these charts show a separation of monograph and serials cataloging into different areas, with two showing serials cataloging in a different department from monograph cataloging. There were no instances of an obvious division along lines of physical format. Three charts seem to indicate that neither publication type nor physical format was an issue at this time; however, it is possible that the detail necessary to see these divisions was simply lacking. In four additional cases, it was impossible to tell anything about the internal division of either or both relevant departments. ${ }^{1}$

SPEC Kit no.129 (published in 1986) is much larger in terms of number of organizations included; however, the results are equally inconclusive because of the lack of relevant detail. This publication includes 61 charts of possible significance for this paper's purpose. Twenty-one charts show a separation of monograph and serials cataloging, 14 of these having serials cataloging and monograph cataloging in different departments. Three of those in the last category also have separate teams or units for the cataloging of non-print or alternate formats. Two charts seem to show that format was not an issue in the determination of cataloging assignments at this time. In the other 38 cases, it was impossible to tell how the catalog and/or serials departments were internally organized. ${ }^{2}$

\footnotetext{
${ }^{1}$ Association of Research Libraries. Systems and Procedures Exchange Center. Organization charts. SPEC Kit, 1. Washington, DC: The Center, updated 1977.

${ }^{2}$ _. Organization charts. SPEC Kit, 129. Washington, DC: The Center, 1986.
} 
The latest SPEC Kit devoted to organization charts is no. 170 (published in 1991). This Kit includes 28 relevant charts, six of which show monograph and serials cataloging as separated, one of which seems to show that format is not an issue, and 21 that are not detailed enough to yield any conclusions. ${ }^{3}$ None of the charts show a separation by physical format. Finally, the Kit devoted to reorganization (published in 1996) proved to be even less useful than those dedicated to organizational charts. The volume's focus on general divisional lines, rather than the internal workings of individual units, did not provide the level of detail necessary for this author's purpose. ${ }^{4}$ Altogether, these sources do not yield enough information to make even an educated guess as to the type of structure that predominates or whether this has changed over time, and it is this author's opinion that a research study on the subject would be an excellent contribution to the field.

Donald Foster, in each edition of his text Managing the Catalog Department, discusses ten "traditional ways" in which such departments may be organized: by material or service, staff specialization, user, location, system or channel, time, process or equipment, function, number, or taskforce. It is interesting to note that his list, descriptions, and conclusions are the same in each edition, published between 1975 and 1987; ${ }^{5}$ however, this is perhaps to be expected because the list covers so many possibilities and is meant to show traditional methods of organization. Most libraries will find that their organizational structure is actually based on a number of these factors and not any one in isolation.

For the purposes of this article, however, the main interest lies in delineations, or the lack thereof, of cataloging assignments (i.e. "who catalogs what") based on physical format and/or publication type. In this author's experience, the most common cataloging divisions with regard to these considerations are of six varieties, which have been labeled according to the system below:

Models 1a-1b: The catalog department includes only monograph cataloging. Serials cataloging is in a separate department, usually with other serials functions. Cataloging, at least of monographs, is usually divided by subject and/or language. In Model 1a, there is no delineation according to physical format of an item (see Figure 1) whereas in Model 1b, cataloging assignments are further divided based on this criterion (see Figure 2).

${ }^{3}$ __. Organization charts in ARL libraries, comp. by Jay Martin Poole. SPEC Kit, 170. Washington, DC: The Center, 1991.

4 _. Library Reorganization and Restructuring, comp. by Joanne D. Eustis and Donald J. Kenney. SPEC Kit, 215. Washington, DC: The Center, 1996.

${ }^{5}$ Foster, Donald L. Managing the Catalog Department. Metuchen, NJ: Scarecrow Press, 1975, pp.148-152; Managing the Catalog Department. 2nd ed. Metuchen, NJ and London: Scarecrow Press, 1982, pp.159-164; Managing the Catalog Department. 3rd ed. Metuchen NJ and London: Scarecrow Press, 1987, pp. 170-175. 
Technical Services

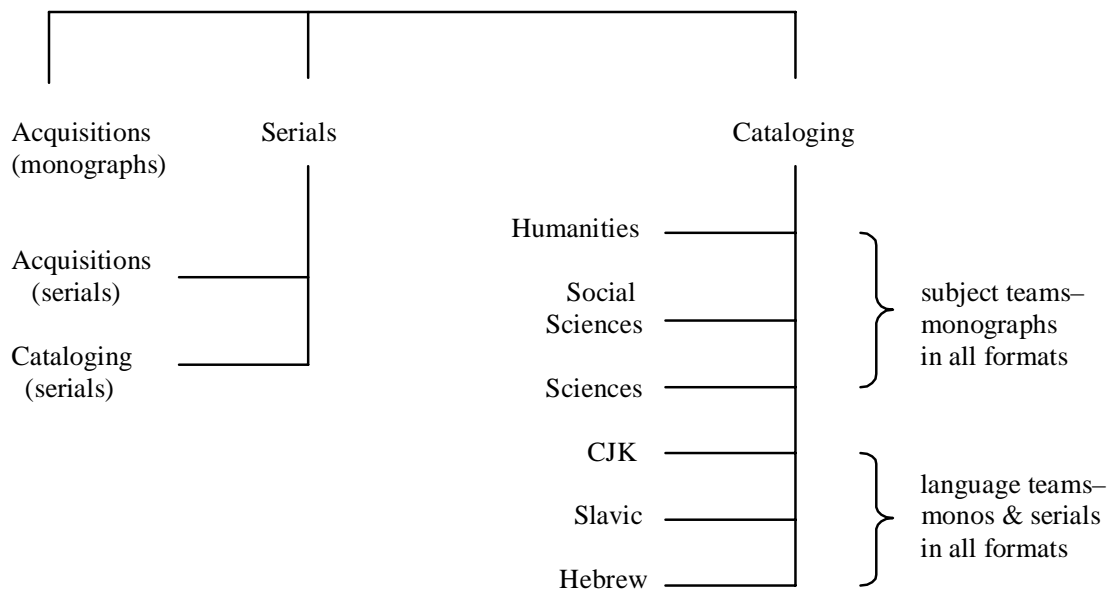

Figure 1: Model 1a

Technical Services

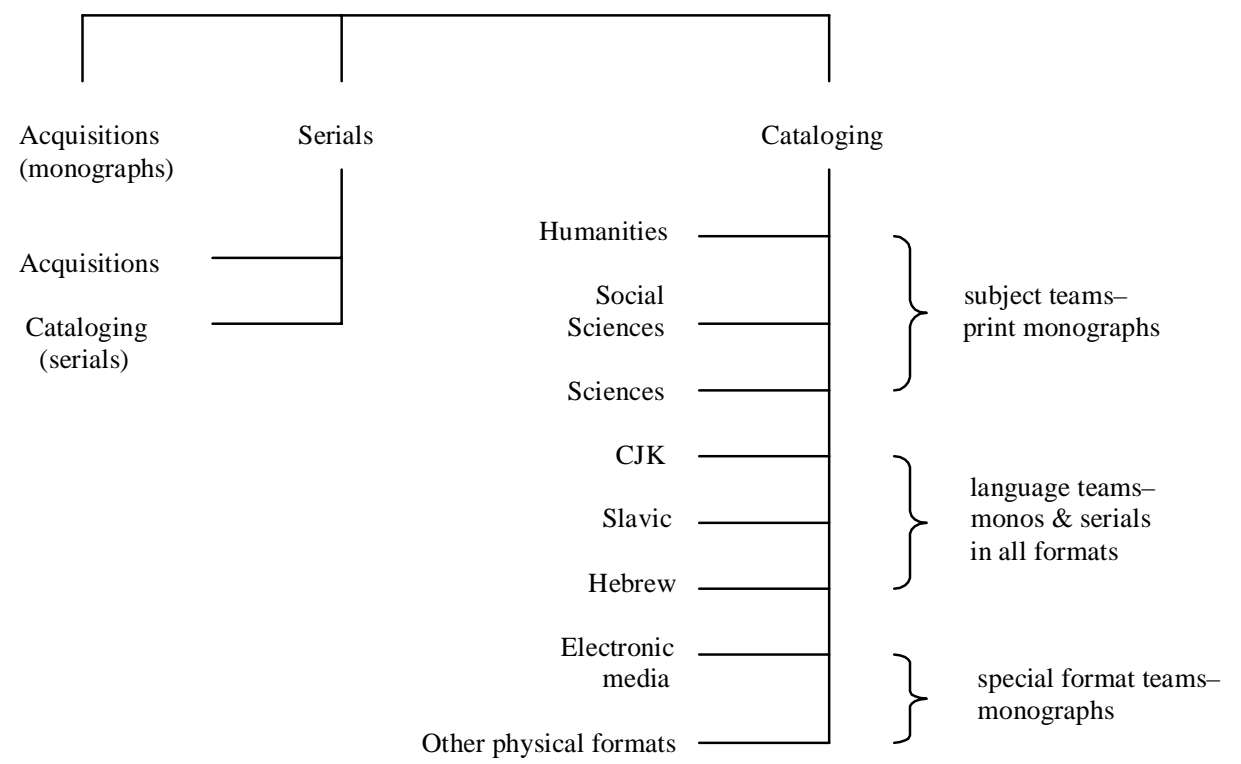

Figure 2: Model 1b

Models 2a-2d: The catalog department includes cataloging of all physical and publication formats, and is organized into teams or units which specialize according to language and/or subject. In Model 2a, further division is made based on physical format (see Figure 3). In Model $2 \mathrm{~b}$, it is instead publication type that is delineated (see Figure 4). In Model 2c, both of these factors are combined in the creation of units/teams and the organization of workflow (see Figure 5). Further elaboration on this option can be found in the section detailing effects of current 
trends on this type of organization. Finally, Model 2d shows workflow divisions based on subject and/or language only, not on publication or physical formats (see Figure 6). In smaller departments there may be no divisions at all, with all catalogers responsible for all types of cataloging.
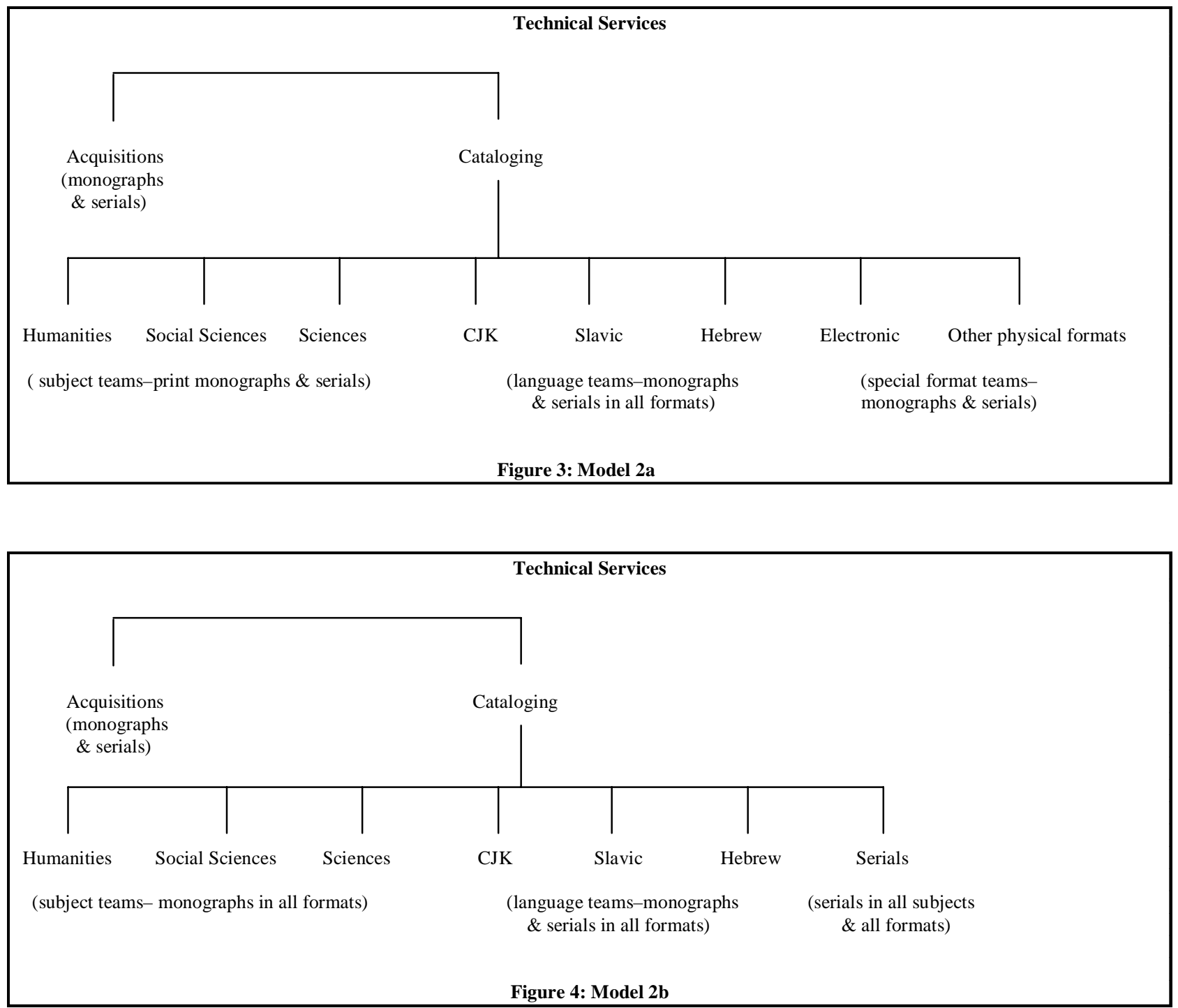

Those institutions that choose to separate serials from monographs and/or make distinctions according to physical format may do so because of perceived differences in the cataloging of these various items. It may be felt that specialization is needed in order to understand all of the intricacies of a particular format and produce the highest quality work in the least amount of time. On the other hand, the decision to organize a cataloging department by subject or language expertise only may result from an assumption that this expertise is more vital. 

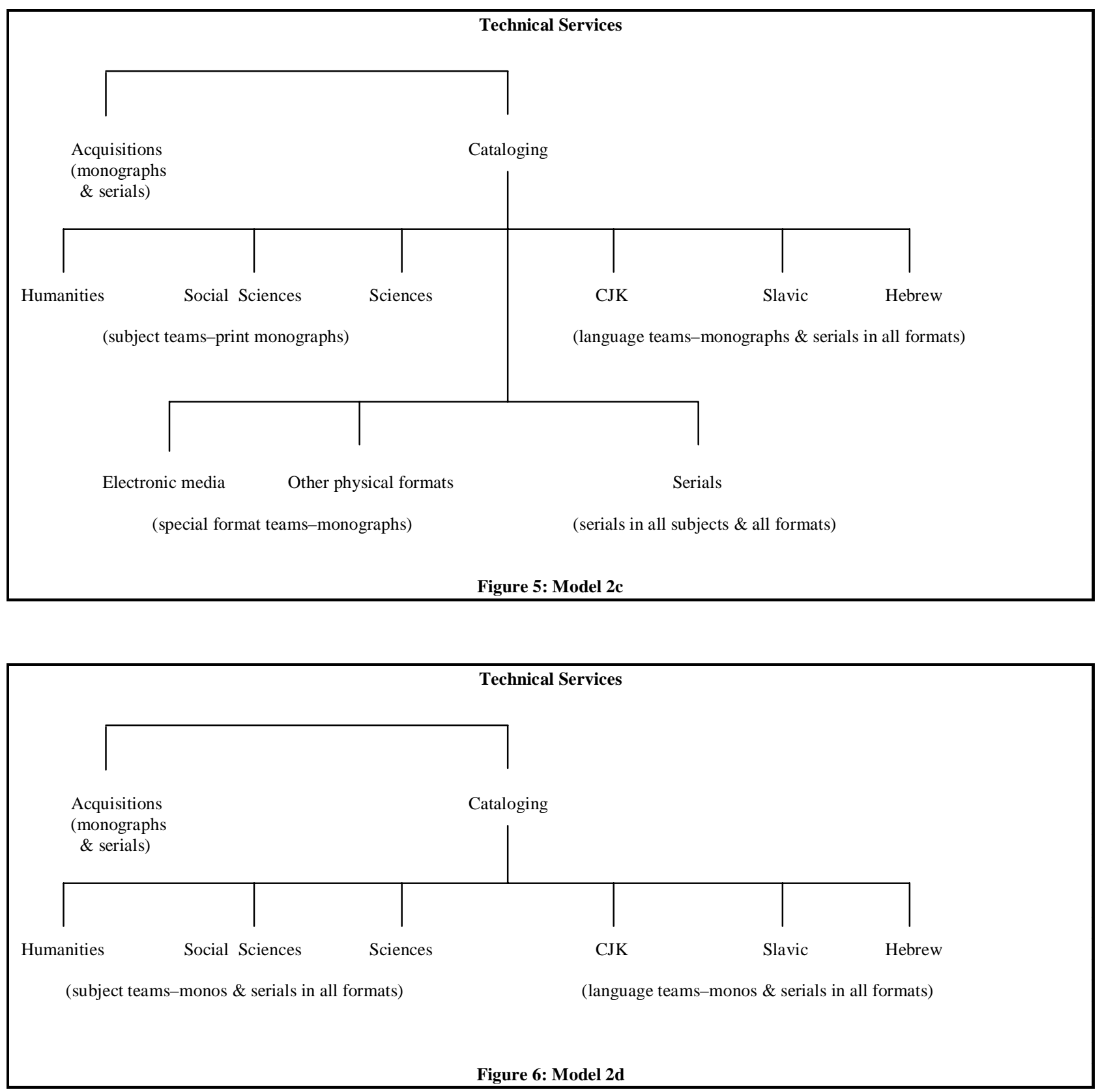

\section{Trends Related to Web Publishing}

The professional literature has included discussion about electronic publishing and its impact on libraries for over a decade, and delving into some of these sources provides an idea of how this field has developed and expanded over the years. For example: Butler tells us in 1987 that "[t]oday, the online market is real for only a few hundred publishers." ${ }^{6}$ At the beginning of 1989 , Morris published the article "Electronic Information and Technology: Impact and Potential for

\footnotetext{
${ }^{6}$ Butler, Brett. "Too Many Trends, Too Few Investments," Electronic Publishing Business, 5 (Feb. 1987), 1.
} 
Academic Libraries." ${ }^{7}$ In 1992, Shreeves published an article discussing "[t]he incorporation of electronic resources in the humanities into the traditional practice of collection development" in academic libraries ${ }^{8}$. By 1995, Okerson was speaking about the "whirlwind development of online serials" ${ }^{9}$ and Johnson said: "[t]he universe of electronic information expands and increases in complexity with astounding speed." ${ }^{10}$ In an article announcing the 6th ed. of the Directory of Electronic Journals, Newsletters and Academic Discussion Lists, ARL's Office of Scholarly Communication reported a 257\% rise in the number of electronic journals during 1996 alone, and the total growth for 1991 to 1996 at over $1400 \%{ }^{11}$ Later, Luther said that "1997 is the year when there is suddenly a multitude of options for electronic journal literature..."12

Luther's statement was substantiated in the 7th ed. of the Directory of Electronic Journals, Newsletters and Academic Discussion Lists, which included a chart detailing the number of electronic publications of various types listed in each edition from 1991 through 1997. The two categories of interest here are e-journals/zines and e-newsletters/other (for the summary included included here, these are called simply journals and newsletters). The earliest edition of the Directory contains 27 journals and 83 newsletters, while the most recent includes 2459 journals and 955 newsletters. The initial boom appears between 1993 and 1994, where the numbers jump from 45 journals and 175 newsletters, to 181 journals and 262 newsletters. In 1995, the numbers are up to 306 and 369 respectively. 1996 shows the numbers at 1,093 journals and 596 newsletters, and 1997 has them at 2459 journals and 955 newsletters. These huge jumps occurred despite of the fact that the Directory had narrowed its scope of coverage over the years, so that it was now excluding many titles available via large package deals and had narrowed its focus overall. $^{13}$

\footnotetext{
${ }^{7}$ Morris, Dilys E. "Electronic Information and Technology: Impact and Potential for Academic Libraries," College \& Research Libraries, Jan. 1989, 56-64.

${ }^{8}$ Shreeves, Edward. "Between the Visionaries and the Luddites: Collection Development and Electronic Resources in the Humanities," Library Trends, 40 (Spring 1992) 579-595.

${ }^{9}$ Wood, Elizabeth J. "At Issue: Dimensions of Seriality in an Electronic World," Library Acquisitions: Practice and Theory, 21 (Winter 1997) 517.

${ }^{10}$ Johnson, Peggy. "Collection Development Policies and Electronic Information Resources," Collection Management for the 21st century: A Handbook for Librarians, ed. G. E. Gorman and Ruth H. Miller. Westport, CT and London: Greenwood Press, 1997, p. 101.

${ }^{11}$ Association of Research Libraries. Office of Scholarly Communication. "Electronic Publishing Explodes on the Web," ARL, 187 (Aug. 1996) 6.

${ }^{12}$ Luther, Judy. "Full Text Journal Subscriptions: An Evolutionary Process," Against the Grain, 9 (June 1997) 18. This article is also avilable in the 7th ed. of the Directory of Electronic Journals, Newsletters and Academic Discussion Lists, 1997, pp. 18-24.

${ }^{13}$ Directory of Electronic Journals, Newsletters and Academic Discussion Lists. 7th ed. Comp. Dru Mogge and Diane K. Kovacs. Washington, DC: Association of Research Libraries, Office of Scientific and Academic Publishing, 1997, p. 3.
} 

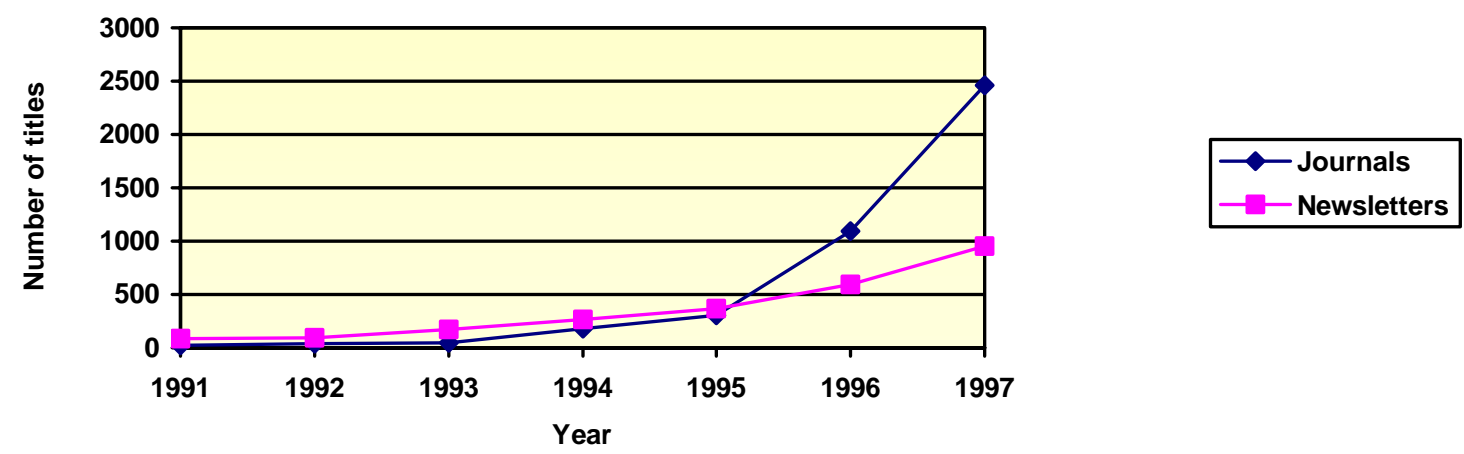

For a more recent indicator, this author turned to the archive for New Jour, a listserv devoted to the announcement of new e-journals and newsletters, and updates/revisions to the same. As of May 31 1999, the archive listed a total of 7792 titles that had been announced via the list since its inception in August 1993. On July 10, this number had increased to $8015 .{ }^{14}$ It seems obvious that many of these "announcements" must in actuality be updates or re-announcements of publications previously listed. Some announced titles may have never reached the publication stage, and others have undoubtedly ceased by now. However, the numbers provide an excellent indication of the amount of activity now occurring in this area.

The heaviest growth in electronic publishing in this decade has occurred in the realm of remote access publications available on the Internet, in more recent years almost exclusively via the Web. It has been said that this growth is due mainly to the fact that more and more publishers of print journals are now offering these publications also in full-text electronic form over the Web. ${ }^{15}$ For many people, this translates into the belief that the growth cannot possibly continue in this manner for much longer. Once all of the print journals have been made available on the Web, things will surely slow down, right? Perhaps, and perhaps not. For at the same time that this argument is made, we also hear that "[l]ibraries do not have any choice about whether to provide access to Internet resources [because] an increasing part of the information needed by their users is only available from the Internet."16 In addition, predictions of decreasing Web publication activity do not seem to take into consideration the number of true monographs (i.e. non-database publications that are not related to serial titles) that are mounted on the Web each year. In fact, this author found that most recent articles and texts dealing with the impact of Web publishing on libraries do so only in regard to electronic journals. Electronic texts of other types are considered much less frequently and usually in terms of digitization as a means of preservation, rather then acquisition and processing concerns.

There is little argument remaining today concerning whether libraries should provide Web access to their patrons, and documents that include information on the increasing electronic collection activities of particular institutions are proliferating. While some are commenting that "[t]he

\footnotetext{
${ }^{14}$ New Jour: Electronic Journals \& Newsletters [Archive]. http://gort.ucsd.edu/newjour/

${ }^{15}$ Directory of Electronic Journals, 1997, p. 3.

${ }^{16}$ Martin, Giles. "Control of Electronic Resources in Australia," Cataloging \& Classification Quarterly. 22 no. 3/4 (1996), 93.
} 
electronic journal is still too recent and untried to be assigned a place within the budget or the collection," ${ }^{17}$ others put a different spin on the issue by instead saying that "libraries have followed traditional methods for selection, acquisition, cataloging, and other processing functions" related to e-journals. ${ }^{18}$ Recent articles and reports concerning collections and programs at particular institutions generally include statements about the importance of electronic collecting and/or access, many of them focusing on this area to the exclusion of all others. ${ }^{19}$ The move toward the "collecting" of remote access materials can be seen in the expanding use of the term "information resource budget" instead of "acquisition budget" or "materials budget." 20 The growth in acquisition of electronic resources of all types can be seen in the growing number of books and journal issues devoted entirely to this subject.

ARL devoted two 1994 volumes of the SPEC Kit series to the topic of Electronic Journals in ARL Libraries. The basis of both volumes was a survey, sent out to member libraries earlier in the year, which gave respondents the opportunity to provide details regarding if, and how, electronic publications were being dealt with in their institution. Obviously, the focus of these publications was much wider than simply Internet publications; however, once again we can use this data as an indicator of where large research libraries were with regards to this area at the time the survey was sent out. Of the 75 respondents, 35 said that they currently collected electronic journals. Although 15 libraries said that they used different selection criteria for this format than for print journals, only five had actual collection development policies in place for electronic journals. $^{21}$

Interestingly, the number of libraries collecting electronic journals had changed very little since a 1992 survey when a similar question was included. At that time, 36 out of 74 respondents reported that they were "involved in" or "subscribing to" electronic journals. This earlier survey also included questions about "digitization of text" and the provision of access to "electronic fulltext" resources. Responses showed that 31 libraries were involved in the former and 49 were involved in the latter. ${ }^{22}$ This survey did not include a question focusing directly on the existence of collection development policies for electronic resources. Although we can assume that the

\footnotetext{
${ }^{17}$ Martin, Murray S. Collection Development and Finance: A Guide to Strategic Library-Materials Budgeting. Frontiers of Access to Library Materials, no. 2. Chicago: ALA, 1995, p. 50-51. Several other sources agree, including: Biernan, Kenneth John. "Costs of Electronic Information," Encyclopedia of Library and Information Science. New York: M. Dekker. 54 (1994) 126.

${ }^{18}$ Association of Research Libraries. Systems and Procedures Exchange Center. Electronic Journals in ARL Libraries: Policies and Procedures, Comp. Elizabeth Parang and Laverna Saunders. SPEC Kit, 201. Washington, DC: The Center, 1994. p. [ii].

${ }^{19}$ For example: Association of Research Libraries. Systems and Procedures Exchange Center. The Emerging Virtual Research Library, by Nancy Schiller. SPEC Kit, 186. Washington, DC: The Center, 1992; Electronic Journals in ARL Libraries: Issues and Trends, Comp. Elizabeth Parang and Laverna Saunders. SPEC Kit, 202. Washington, D.C.: The Center, 1994; Electronic Journals in ARL Libraries: Policies and Procedures; Hudson, Laura and Windsor, Laura. "Providing Access to Electronic Journals: The Ohio University Experience," Against the Grain, 10 (June 1998) 1+

${ }^{20}$ For instance: Ungern-Sternberg, Sara von and Lindquist, Mats G. "The Impact of Electronic Journals on Library Functions," Journal of Information Science. 21 (1995) 396; Perryman, Wayne R. "The Changing Landscape of Information Access: The Impact of Technological Advances Upon the Acquisition, Ownership, and Dissemination of Informational Resources Within the Research Library Community," Managing Technical Services in the 90's, ed. Drew Racine. Haworth, 1991. pp.73-93. (Also published as: Journal of Library Administration 15 (1991), 73-94).

${ }^{21}$ Electronic Journals in ARL Libraries: Policies and Procedures, p. [i].

${ }^{22}$ Emerging Virtual Research Library, p. 3.
} 
types of electronic resources being discussed varied between the earlier and later surveys, the similarity of the numbers is of at least minor interest.

\section{Impact of these trends on cataloging functions}

What is the relationship between trends in Web publishing and the ways in which libraries organize cataloging activities? Quite simply, the former has a profound effect on the latter. In the early 1990s, there were claims that integrating electronic resources into existing departments and workflows, using existing staff and staffing levels, could be done "without changes in procedures and [with only] small adjustments in handling." ${ }^{23}$ But in the mid 1990s Web publishing began to truly flourish, and it has since grown much larger than anyone speaking from that earlier time could have imagined. The early, optimistic views understandably did not foresee the later proliferation of this medium, or the important role that Web publications would have in libraries. In more recent years, the major point of most literature on this topic has been that libraries must be prepared to make changes to meet the challenge of providing access to Web resources. Most of these sources, however, say nothing about how to do this-only that it must be done.

As with all areas related to the Web, there are numerous articles and reports that discuss the impact of Web publications on technical services and/or cataloging. Unfortunately, those sources that deal with cataloging issues focus almost entirely on the actual cataloging process and rules, and make no mention of how best to organize the cataloging "machinery" to get the job done. When this author suggested including such a session in a conference devoted to cataloging of electronic resources, the idea was immediately turned down as being "off-topic."

To those of us working in medium- to large-sized libraries that are actively collecting Web resources, organization of cataloging functions related to this medium is extremely "on-topic." We can readily see the effects of the current situation on our library's cataloging operations and we are actively looking for solutions. The effects on cataloging stem from two separate, but related, issues. First, many of these publications are online monographic databases issued as "electronic versions" or "equivalents" of paper serials. Second, many libraries are selecting these Web publications, either as second "copies" of a title or as replacements for their print counterparts. As these trends continue, libraries will be acquiring more resources that, while they do not fit neatly into any definition currently authorized in the cataloging world, are now defined as monographs according to the rules. In addition, print serial publications may be cancelled or simply never purchased in the first place, thus causing a continuing decline in the number of serials being acquired or renewed. Since catalog departments catalog those resources that are acquired by their library, there is naturally a corresponding shift occurring in the quantity and nature of publications finding their way through cataloging workflows.

Catalogers today are faced with the reality of having to provide catalog access to hundreds of Web publications, often acquired all at the same time through a "package deal", while continuing with the other work they have been doing all along because, for the time being at least, the acquisition of paper and other "traditional formats" is not decreasing in equal measure to the increase of online acquisitions. (Of course, this may change as more print serials are cancelled or

\footnotetext{
${ }^{23}$ McMillan, Gail. "Technical Services for Electronic Journals Today," Serials Review. v. 17, no. 4 (1991) 86.
} 
cease publication.) In addition, as positions are lost through downsizing or left vacant for extended periods, many cataloging operations find they now have fewer staff resources with which to meet this challenge. Opting to use CONSER's "single-record option" in the case of electronic journals may ease some of the burden, but providing even this level of catalog access to such a large number of resources can be extremely labor-intensive. A combination of some or all of these factors makes organizational structure a topic of prime importance to many of today's catalogers.

Almost everyone in this situation is working in institutions where cataloging functions are arranged according to one of the traditional models outlined above. Thus the question becomes: how well do these traditional models respond to the Web publishing and collection development environments of today? Obviously, the success of any department or unit depends in part on the personnel within it; however, organizational structure plays a key role in determining the quantity of cataloging of a particular type that can be accomplished within a set period of time. In this section, each of the traditional models will be explained in more detail, including discussion as to how each model is affected by the trends outlined previously. Finally, several courses of action will be discussed and recommendations given regarding which, if any, is the best solution to the problem. The pros and cons of each organizational model are summarized in the Appendix.

\section{Model 1}

In this scenario, cataloging is performed in different departments depending on the publication type (monograph or serial) of the resource being cataloged. Criteria such as language and/or subject generally are a factor in monograph cataloging departments of larger institutions. These same criteria may or may not be a factor for the department handling serials cataloging. The separation of cataloging by publication type may break down when the materials in question are in certain languages (for instance, those in non-Roman scripts) so that one team or unit may catalog everything in a particular language, both monographs and serials. This type of basic structure can be further organized according to one of two different options.

With Model 1a, physical format of resources is not a factor in deciding the question of "who catalogs what." The impact of current trends on this type of structure stems from two factors. First, titles that are serials when issued in paper frequently become monographic databases when issued online. Second, some libraries are deciding to cancel or never receive paper subscriptions in favor of acquiring their online "equivalents." In institutions that create separate records for all Web publications selected by subject specialists, the bulk of the workload from acquisitions in this format will be seen in the department that handles monograph cataloging. The lack of separation based upon physical format means that the impact is spread among all monograph catalogers. Serials cataloging units will see a more manageable number of Web publications and a recognizable growth in the number of recataloging requests related to cessation of paper titles. On the other hand, those institutions opting for CONSER's "one-record approach" will most likely see the major impact of these trends in the department responsible for serials cataloging. ${ }^{24}$ In the author's experience, the majority of selected Web resources are actually electronic versions

\footnotetext{
${ }^{24}$ For an explanation of CONSER's "one-record approach", see: "Interim Guidelines for Online Versions of Printed Serials", in CONSER Cataloging Manual, Module 31, 31.3.5.
} 
of serial titles also received in paper. If this trend continues, then libraries using the one-record technique will find that most of their Web acquisitions will be noted on serial records, rather than cataloged according to their own publication type. In addition, the serials catalogers will also need to deal with the increase in cessation of paper titles. Monograph catalogers in this scenario will see a small number of electronic monographs coming through the department, and these will be split among all monograph cataloging teams/units.

With Model 1b, physical format of a resource is added as one of the deciding factors in the routing of materials through the monograph cataloging department. It may also be a factor in the department that handles serials cataloging. Physical format is usually taken into consideration along with other characteristics of a resource, with the result that cataloging of all items in a certain language or subject may occur in one team/unit, while cataloging of items in other languages and/or subjects may be broken out according to physical format. For instance, there might be separate units/teams to catalog audio-visual materials, computer files, microform, rare books, and maps, while music, CJK, Hebrew, Slavic or other specialized subject/language material may each have centralized cataloging in one team/unit regardless of format. The impact on this type of structure is similar to that for Model 1a. In addition, the unit within each department responsible for computer files may be inundated with more work in a year then they have seen in the last ten years altogether! If either department has, instead, a unit that is responsible for the cataloging of all "alternate" formats, this increase comes on top of the need, or at least the desire, to keep up with the rest of their work as well. It doesn't take a great mind for mathematics to realize the effect of this! If staffing levels in the unit stay the same, cataloging of all Web publications selected by the library will likely remain an elusive goal for that particular institution.

\section{Model 2}

The basic structure of this model has all cataloging centralized in one department. Within that department, staff may be organized in one of four different ways. In Model 2a, workload is divided according to the physical format of the material being cataloged. As in other cases, subject and/or language expertise may also be a factor and may result, by necessity, in a particular unit cataloging material in all formats. Publication type is not an issue in this type of structure. In this scenario, when an institution opts to catalog Web resources on separate records, the bulk of this work ends up in the unit/team responsible for cataloging computer files and the impact of cessation of paper serials is spread among all of the other units/teams. Again, the effect of this should be readily recognizable. Without an infusion of additional personnel, it is highly unlikely that an already existing unit will be able to handle the influx of new cataloging requests. If, on the other hand, the institution chooses to go with the one-record approach, the workload is spread among all units responsible for print and computer file material. The unit cataloging computer files may still experience an increase in workload because of the acquisition of items in electronic format only, but it will not be inundated until or unless paper titles begin ceasing on a much more frequent basis.

Model $2 \mathrm{~b}$ begins again with the same centralized department and then delineates workload by publication type instead of physical format. Larger departments usually further divide monograph cataloging into teams/units according to subject and/or language. Serials cataloging 
generally resides in one team only. Again, the requirements of particular languages or subjects may cause this division to break down. The impact of Web publishing and collection of Web resources on this type of structure is identical to that of Model 1a and is affected in the same way by the same cataloging and collection development decisions.

With Model 2c, both publication type and physical format are factors in delineating workflow. The current University of Oregon Catalog Department is one example of this type of organization. The Department includes several monograph teams specializing in different formats or languages, including a 1.5 FTE team that catalogs all Roman-alphabet monographs that are in other than traditional print form, and a 4.0 FTE team that catalogs all Roman-alphabet serials, regardless of physical format. The impact on this type of structure is the same as that in Model 1b.

Finally, the scenario of Model 2d shows a department where decisions concerning "who catalogs what" do not take into consideration either publication type or physical format. In small departments there may be no divisions at all, with all catalogers responsible for all types of cataloging. The result in this case should be a true equalization of impact as far as Web-related trends are concerned. In most larger departments, however, divisions based on subject and/or language will remain and, if current trends continue, an inequality of workload will still exist. This will be particularly true for libraries that collect in the sciences, because of a continual increase in the number of science titles being published on the Web and collected in this format, coupled with the continued publication and collection of new print science journals. These trends are much more pronounced in the sciences and so the result will be a much greater increase to the workload of the unit responsible for this area. ${ }^{25}$ It seems reasonable, however, to consider this inequality to be part of the uniqueness of particular subjects and something that is to be expected. Just as the cataloging of sound recordings will be found mainly in the subject team devoted to music, so will the cataloging of Web publications be found more often in science subject teams, and microform cataloging found more often in humanities subject teams. The more serious inequality will be in the overall amount of work expected of science catalogers in libraries that collect heavily in this subject.

\section{What are the options?}

At this point, the reader may have the following response: "That's great, but I already know the problems! Why doesn't somebody tell me what to do about it?" This section will present and analyze several options related to the traditional models already discussed and, finally, offer one that this author believes to be "The Better Solution."

\section{The Obvious "Solution"}

The Model 2d scenario showing no delineations of workload based on any pre-determined criteria may at first glance seem like the perfect approach to the problems being discussed. The beauty of this "generalist" approach to cataloging is that it assures an equalized workload among

\footnotetext{
${ }^{25}$ These statements are based solely on the personal experience of the author, and not on findings gleaned from the literature.
} 
all catalogers regardless of what new publishing trends emerge, or which fund lines have the most new money in a given year.

But is such a system left unaffected by the publishing and collecting shifts we are seeing today? Of course not! The difference is that all catalogers are affected, not just a few. This may be considered one asset of the model since the extra workload does not fall to a small number of people. However, training everyone and keeping them up-to-date on all existing formats and publication types, plus any new ones that come along, is a daunting task that becomes more complicated the larger the department. In a true generalist system all catalogers are trained to the same level for the cataloging of all formats, including those (such as online publications) for which the rules seem to be constantly changing. There may be a resource person for each format; however, everyone must be able to handle all of them on a routine basis. Considerable stress is put on such a system when a new format with new rules is added to the mix.

Even more importantly from a patron service viewpoint, the lack of specialization in this type of organization may mean that it will take longer to catalog certain types of publications and that overall quality will probably be lower. Is it worth it? It may depend on the situation, but this author thinks probably not. Quality and timeliness are the two most important considerations of what we in cataloging "do," and, in the author's opinion, when a generalist approach is taken in a large institution both of these considerations suffer to an unacceptable degree.

\section{What About the Other "Traditional" Structures?}

Which of the other traditional structures are better equipped to handle current trends? The models that show delineation based upon either publication type (1a and 2b) or physical format (2a) result in more equalization of workload than those which take into account both of these criteria in determining cataloging assignments. There are other positive aspects of these options as well. If, for instance, routing decisions based upon whether something is defined as monograph or serial are eliminated, you bypass, as far as cataloging workflow is concerned, the problem of paper serial titles turning into online monographic databases. The same catalogers will be responsible for both, so publication type is not an issue until it is time to determine the actual cataloging rules to be followed. If, instead, delineations based on physical format are eliminated and those based on publication type are retained, you now have more people who can catalog Web publications. Moreover, if you catalog them on separate records, most will be routed to monograph catalogers rather than to serials catalogers. One positive aspect of this approach is that there are usually many more monograph catalogers at a given institution than there are serials catalogers, so workload will, in reality, be more equally divided than may first seem to be the case.

Of course, all of the problems of these approaches, outlined previously, still apply. In each case, one factor remains to cause an unequal workload. Both of them require, for institutions not currently set up this way, major changes for the department and the individuals within it. Both of them may result in some benefit but, because of issues related to staff and training, it will probably be a long time before that benefit is realized. And, equally important, both have an effect on far more than just the cataloging of Web publications, because all materials will be divided according to these new lines--not just the ones that are causing such problems today. 
This means that training will be much more complex than simply teaching everyone to catalog Web resources. Before making a decision to change organizational structure in this way it must be decided, with certainty, that the model to be adopted works well for all materials in all formats, and that the benefits outweigh the costs.

\section{The Better Solution}

Is there any solution that works better than the ones already discussed? This author thinks that the answer may be found by taking a rather different approach, one that makes use of the positive aspects of the previously outlined structures while at the same time minimizing the negatives. Traditional cataloging models rely on certain delineations that are usually viewed as all or nothing propositions. Those delineations, and the particular structures that arise from them, have already been dealt with in detail. The solution to the present problem lies in altering the view that these delineations must be equally adhered to for all formats throughout a particular organization. All formats are not created equal, and they do not all fit neatly into the box we have created for them. The solution, then, is to alter the shape of the box to fit the demands of a new format.

What is needed to successfully deal with the current Web publishing and collecting environment? Simply stated, many more people must be trained to catalog publications in this format and these same people must continue with their current work, whatever that might be. Organizational, and in some cases departmental, lines need to bend. The precise nature of this bending will depend in part on the organizational model in use. In other words, the proposed solution will necessitate a substantial change in philosophy for some institutions but fall neatly into current operations at others. The details will also vary depending on whether or not the "onerecord approach" is being used whenever possible to provide catalog access to Web publications.

For institutions that are using the one-record approach, the solution relies primarily on training monograph catalogers in this procedure and authorizing them to make these types of changes to serial records, while at the same time retaining current specialties and workflow for other formats. This will require a conceptual change on the part of staff in organizations that separate cataloging assignments based upon publication type. Separation of cataloging assignments along these lines often means that monograph catalogers have been instructed not to edit serial records (and vice versa, of course). Many of them may also have picked up the idea that serials are a beast best avoided at all costs. In institutions starting from this point, monograph catalogers will need to understand serial records better than they currently do, and they will need to overcome their negative feelings about serials work. Serials catalogers in this environment will need to give up their sense of ownership concerning serial records in the database, and allow a certain level of "demystification" of serials processes to occur. They may also need to develop a higher level of trust in the ability of others outside of their own unit or department, and overcome the idea that only serialists should be allowed to alter serial records. All of these concerns can be met by communicating the fact that when the one-record approach is used, Web publications are not being cataloged, but rather simply noted on the record for the paper version. The amount of training needed to allow monograph catalogers to add the few fields necessary in processing Web publications according to this approach should be minimal, and it will not be necessary to teach them how to catalog serials in order to follow this approach. 
For those publications that are not issued or acquired in both print and online versions, and for those institutions that are cataloging all of their Web acquisitions on separate records, the solution is again to train all catalogers in the cataloging of this format, while at the same time having them retain current specialties and workflow for other formats. The exact outcome in this case, i.e. the level of effectiveness of the solution, will depend upon the organizational model in use and whether delineation based on publication type will be a factor in the routing of Web publications. However, there should be noticeable improvement in organizations following any of the traditional models.

The defining factor, regardless of the type of cataloging being input for Web resources, is that of having cataloging staff continue with current specializations and assignments when cataloging material in other formats. The reason this author feels it is the "better solution" is because it successfully deals with the problems associated with Web publishing and collecting while at the same time maintaining the status quo in other areas. There is no requirement to train all catalogers in the cataloging of all formats and/or publication types, so the amount of time needed to implement this solution is much less than going with one of the options outlined previously. The negative aspects of the generalist solution are also avoided. This solution gives staff an opportunity to broaden their horizons but does not require them to give up working in their areas of specialization and does not disrupt satisfactory workflows that are already in place for other types of material. Finally, and perhaps best of all, it is a solution that can easily be rethought or undone if those people who believe the current situation is temporary end up being correct!

\section{Conclusion}

Cataloging functions have traditionally been organized according to the physical and/or publication format of items being cataloged. The recent rise of the Web, and accompanying proliferation of Web publishing, has had a profound impact on both of these characteristics, so that traditional organizational models are no longer as effective as they once were. Some of these models work better in this environment than do others; however, none are truly equipped to deal well with the changes that have occurred.

The magnitude of the Web cataloging "problem," and the strain that it puts on cataloging resources as they are currently organized in most libraries, can seem overwhelming to managers trying to fit this new format into their organizational structure. The situation is not untenable, however, nor does it require that a library entirely give up its current model of functioning. The size of the problem, and the lack of resources to hire additional personnel to specialize in this format, necessitate some alteration of current cataloging assignments. A basic conceptual change regarding how these assignments are made is also necessary in order to reap the most benefits in the least amount of time. The answer lies in the adoption of an approach that enables staff to learn those things necessary in order to provide catalog access to Web publications, while at the same time allowing them to continue doing work that is familiar to them. Such an approach will succeed in meeting the needs of the current environment, and will do so with a minimum of upheaval. 